\title{
Short Segment Hiatal Hernia: Is It a Clinically Significant Entity?
}

\author{
Jong Jin Hyun, M.D., Ji Hoon Kim, M.D., Jong Eun Yeon, M.D., Jong-Jae Park, M.D., Jae Seon Kim, M.D., Kwan Soo Byun, \\ M.D., and Young-Tae Bak, M.D.* \\ Department of Gastroenterology, Korea University Guro Hospital, Seoul, Korea
}

\section{Introduction}

Hiatal hernia (HH) is a well-known contributory factor of gastroesophageal reflux disease (GERD). However, studies on the clinical significance of simple small $\mathrm{HH}$ are lacking. We conducted a study to clarify the clinical significance of short segment $\mathrm{HH}$ (SSHH) in relation to GERD.

\section{Methods}

4,592 consecutive cases (male/female: 2,076/2,516, median age: 49 years) examined with diagnostic esophagogastroduodenoscopy for the first time were enrolled. During the insertion of endoscope, presence of $\mathrm{HH}$ was determined and the length was measured, if present. The relationships between gender, age, presence of erosive esophagitis, and columnar-lined esophagus (CLE) and the lengths of $\mathrm{HH}$ were analyzed.

\section{Results}

Among 4,592 cases, HH was present in 428 cases (9.3\%); SSHH was found in 255 cases (5.6\%) and long segment HH (LSHH) in 173 cases (3.8\%). HH was more frequent among males and patients with $\mathrm{LSHH}$ tended to be older. Erosive esophagitis was observed in $4.8 \%, 22.0 \%$, and $37.0 \%$ of no $\mathrm{HH}, \mathrm{SSHH}$, and LSHH group, respectively $(\mathrm{p}<0.05)$. CLE was observed in $14.4 \%$, $36.5 \%$, and $24.3 \%$ of no HH, SSHH, and LSHH group, respectively $(\mathrm{p}<0.05)$.

\section{Conclusions}

SSHH is not a clinically silent and "innocent entity," but rather a condition with a significant pathologic significance similar to $\mathrm{LSHH}$ in regard to GERD.

(J Neurogastroenterol Motil 2010;16:35-39)

Key Words

Hiatal hernia, Gastroesophageal reflux disease, Erosive esophagitis, Columnar-lined esophagus

\section{Introduction}

Sliding type hiatal hernia $(\mathrm{HH})$ is a condition in which the gastroesophageal junction (GEJ) and some portion of the stomach are displaced above the diaphragm. ${ }^{1,2}$ HH impairs lower esophageal sphincter (LES) function and esophageal acid clearance. ${ }^{1-6}$ Therefore, it predisposes to gastroesophageal reflux dis-

Received: November 15th, 2009 Accepted: November 26th, 2009

(c) This is an Open Access article distributed under the terms of the Creative Commons Attribution Non-Commercial License (http://creativecommons. org/licenses/by-nc/3.0) which permits unrestricted non-commercial use, distribution, and reproduction in any medium, provided the original work is properly cited.

*Correspondence: Young-Tae Bak, M.D.

Department of Gastroenterology, Korea University Guro Hospital, 97 Gurodong-gil, Guro-gu, Seoul 152-703, Korea Tel: +82-2-2626-1778, Fax: +82-505-115-1778, E-mail: drbakyt@korea.ac.kr

Financial support: None.

Conflicts of interest: None. 
ease (GERD), potentially resulting into erosive esophagitis, Barrett's esophagus, and possibly esophageal adenocarcinoma. ${ }^{4,71}$ There have been studies on the relationship between $\mathrm{HH}$ and GERD proving $\mathrm{HH}$ to be an important contributory factor for GERD. ${ }^{4,7,8,11-13}$ However, most of these studies have been carried out with $\mathrm{HH}$ s measuring greater than $2.0 \mathrm{~cm}$ in length, hence the clinical significance of a simple small $\mathrm{HH}$, which we defined as a short segment $\mathrm{HH}(\mathrm{SSHH})$ measuring less than $2.0 \mathrm{~cm}$ in length, has been less studied and not understood clearly. It is generally believed that SSHH usually does not cause symptoms in many patients and is clinically insignificant. ${ }^{4,14}$ Therefore, this study was conducted to see whether SSHH is only a minor anatomic abnormality that bears little or no clinical significance, or a clinically significant entity specifically in relation to GERD.

\section{Materials and Methods}

\section{Patients}

4,592 consecutive cases examined with diagnostic esophagogastroduodenoscopy for the first time at Korea University Guro Hospital, Seoul, Korea by various indications were enrolled as subjects from September, 1999 to November, 2004. 2,076 cases $(45.2 \%)$ were males and median age of the cases was 49 years (36-60 years in inter-quartile range). Cases that had history of digestive tract surgery were excluded. Written informed consent to the study was obtained from each patient and the study was conducted in accordance with the Helsinki Declaration and was approved by the Institutional Review Board at Korea University Guro Hospital (IRB approval No. GR0987-001).

\section{Endoscopy}

Three models of UGI endoscopes were used for this study (GIF-XQ240, XQ260, and Q260, Olympus Medical Systems, Tokyo, Japan). To determine the presence of $\mathrm{HH}$ and columnar-lined esophagus (CLE), the subjects were uniformly observed while the endoscope was being inserted. Minimal amount of air was transferred during insertion, just enough to aid the vision. To avoid inaccurate measurements, patients were asked to breathe slowly with shallow breathings and the procedure was performed carefully so that the patients would not retch or belch.

GEJ was defined endoscopically as the distal end of longitudinally arrayed capillaries of palisade $z o n e^{15}$ or, if it was unclear, the proximal end of the gastric type mucosal folds was used instead. ${ }^{16} \mathrm{HH}$ was diagnosed if GEJ was located at least $0.5 \mathrm{~cm}$ proximal to the level of the diaphragmatic pinchcock action. Endoscopic CLE was diagnosed if squamocolumnar junction (SCJ) was located at least $0.5 \mathrm{~cm}$ proximal to the level of the distal end of capillaries in palisade zone. Endoscopic reflux esophagitis was diagnosed and graded according to the Los Angeles (LA) classification. $^{17}$

When $\mathrm{HH}$ was present, its longitudinal length was measured endoscopically from the GEJ to the diaphragmatic indentation with the insertion length of endoscope at the incisor guiding as the measurement point. All measurements were performed by a single experienced endoscopist (YTB). HH was divided into two grades: $\mathrm{SSHH}$, if the length was shorter than $2.0 \mathrm{~cm}$ and long segment $\mathrm{HH}(\mathrm{LSHH})$, if its length was $2.0 \mathrm{~cm}$ or longer. $\mathrm{HH}$ shorter than $0.5 \mathrm{~cm}$ in length was neglected.

The relationships of gender, age, presence of erosive esophagitis, and presence of CLE with the lengths of $\mathrm{HH}$ were analyzed.

\section{Statistical methods}

All statistics were generated by using SPSS program (SPSS v13.0 for Windows, Chicago, IL, USA), and the data were analyzed using chi-square test or Mann-Whitney $\mathrm{U}$ test. It was considered statistically significant if the p-value was less than 0.05 .

\section{Results}

\section{Hiatal hernia}

Among total of 4,592 cases, $\mathrm{HH}$ was present in 428 (9.3\%); $\mathrm{SSHH}$ in 255 (5.6\%) and LSHH in 173 (3.8\%) subjects (Table 1).

\section{Gender}

Of the 4,592 cases, 2,076 (45.2\%) were males and 2,516 (54.8\%) were females. When compared to the cases without $\mathrm{HH}$ (43.6\%), the proportion of males was higher in $\mathrm{SSHH}$ (59.6\%, $\mathrm{p}$ $<0.001)$ and LSHH (62.4\%, p $<0.001)$ groups (Table 1).

Table 1. Gender and the Status of Hiatal Hernia, n (\%)

\begin{tabular}{llccl}
\hline Gender & \multicolumn{1}{c}{ No HH } & \multicolumn{1}{c}{ SSHH $^{\mathrm{a}}$} & LSHH & \multicolumn{1}{c}{ Total } \\
Male & $1,816(43.6)$ & $152(59.6)$ & $108(62.4)$ & $2,076(45.2)$ \\
Female & $2,348(56.4)$ & $103(40.4)$ & $65(37.6)$ & $2,516(54.8)$ \\
Total & 4,164 & 255 & 173 & 4,592 \\
\hline
\end{tabular}

${ }_{\mathrm{p}}^{\mathrm{a}}<0.001$ vs. No HH.

$\mathrm{HH}$, hiatal hernia; SSHH, short segment hiatal hernia; LSHH, long segment hiatal hernia. 
Table 2. Age of Cases according to the Status of Hiatal Hernia, Median Year (IQR)

\begin{tabular}{cccc}
\hline No HH$^{\mathrm{a}}$ & SSHH $^{\mathrm{a}}$ & LSHH & Total \\
\hline $49(39.0-59.1)$ & $47(36.1-57.0)$ & $54(41.0-66.5)$ & $49(39.0-59.0)$ \\
\hline
\end{tabular}

${ }_{\mathrm{p}}^{\mathrm{a}}<0.001$ vs. LSHH

$\mathrm{IQR}$, inter-quartile range; $\mathrm{HH}$, hiatal hernia; $\mathrm{SSHH}$, short segment hiatal hernia; LSHH, long segment hiatal hernia.

Table 3. Grade of Erosive Esophagitis according to the Status of Hiatal Hernia, n (\%)

\begin{tabular}{lccccc}
\hline \multicolumn{2}{l}{ Erosive esophagitis } & No HH & SSHH & LSHH & Total \\
\hline Present LA-A & $116(2.8)$ & $33(12.9)$ & $22(12.7)$ & $171(3.7)$ \\
& LA-B & $74(1.8)$ & $23(9.0)$ & $33(19.1)$ & $130(2.8)$ \\
& LA-C & $8(0.2)$ & $0(0)$ & $6(3.5)$ & $14(0.3)$ \\
& LA-D & $0(0)$ & $0(0)$ & $3(1.7)$ & $3(0.1)$ \\
& Subtotal & $198(4.8)$ & $56(22.0)^{\mathrm{a}}$ & $64(37.0)^{\mathrm{a}, \mathrm{b}}$ & $318(6.9)$ \\
Absent & $3,966(95.2)$ & $199(78.0)$ & $109(63.0)$ & $4,274(93.1)$ \\
Total & 4,164 & 255 & 173 & 4,592
\end{tabular}

${ }_{\mathrm{p}}^{\mathrm{a}}<0.001$ vs. No HH, ${ }^{\mathrm{b}} \mathrm{p}=0.001$ vs. SSHH.

$\mathrm{HH}$, hiatal hernia; SSHH, short segment hiatal hernia; LSHH, long segment hiatal hernia; LA, grade of reflux esophagitis according to Los Angeles classification.

Males were more likely to have $\mathrm{HH}$ compared to females.

\section{Age}

The median age (inter-quartile range) of the cases without $\mathrm{HH}$, with SSHH, and with LSHH was 49 years (39.0-59.1), 47 years (36.1-57.0), and 54 years (41.0-66.5), respectively (Table 2). Age of the cases with $\mathrm{LSHH}$ was higher than those without $\mathrm{HH}$ or with $\mathrm{SSHH}(\mathrm{p}<0.001)$.

\section{Reflux esophagitis}

Erosive esophagitis was observed in $4.8 \%, 22.0 \%$, and $37.0 \%$ of the subjects without $\mathrm{HH}$, with $\mathrm{SSHH}$, and with $\mathrm{LSHH}$, respectively (Table 3). Erosive esophagitis was more prevalent in cases with $\mathrm{HH}$ than those without $\mathrm{HH}(\mathrm{p}<0.001)$. Among the subjects with $\mathrm{HH}$, erosive esophagitis was more prevalent in LSHH group than SSHH group $(p=0.001)$. Proportion of the cases with LA-A grade erosive esophagitis was similar between the $\mathrm{SSHH}$ and LSHH groups (12.9\% vs. $12.7 \%$; p = 0.512 ). However, cases with higher grades (grade $\mathrm{B}$ or higher) of esophagitis were found more frequently in LSHH group (9.0\% vs. $24.3 \%$; $<<0.001)$.
Table 4. Status of Columnar-lined Esophagus according to the Status of Hiatal Hernia, n (\%)

\begin{tabular}{ccccr}
\hline $\begin{array}{c}\text { Columnar-lined } \\
\text { esophagus }\end{array}$ & No HH & SSHH $^{\mathrm{a}, \mathrm{b}}$ & LSHH $^{\mathrm{a}}$ & Total \\
\hline Present & $598(14.4)$ & $93(36.5)$ & $42(24.3)$ & $733(16.0)$ \\
Absent & $3,566(85.6)$ & $162(63.5)$ & $131(75.7)$ & $3,859(84.0)$ \\
Total & 4,164 & 255 & 173 & 4,592 \\
\hline
\end{tabular}

${ }_{\mathrm{p}}^{\mathrm{a}}<0.001$ vs. No HH, ${ }^{\mathrm{b}} \mathrm{p}=0.011$ vs. LSHH.

$\mathrm{HH}$, hiatal hernia; SSH, short segment hiatal hernia; LSHH, long segment hiatal hernia.

\section{Columnar-lined esophagus}

CLE was observed in $14.4 \%, 36.5 \%$, and $24.3 \%$ in groups without $\mathrm{HH}$, with $\mathrm{SSHH}$, and with LSHH, respectively (Table 4). CLE was more frequently found in groups with $\mathrm{HH}(\mathrm{SSHH}$ and $\mathrm{LSHH}$ ) compared to the group without $\mathrm{HH}(\mathrm{p}<0.01)$. Between SSHH and LSHH groups, the detection rate of CLE was significantly higher in SSHH group ( $p=0.011)$.

\section{Discussion}

Sliding type $\mathrm{HH}$ is a condition in which the GEJ and the proximal part of the stomach are moved upward through the esophageal hiatus above the diaphragm. ${ }^{1,18}$ The relationship between the presence of $\mathrm{HH}$ and GERD has evolved over the past decades since its association has first been emphasized by Allison in 1951, and for about 20 years that followed, HH was used synonymously with GERD. ${ }^{18}$ However, as the use of manometry became widespread, the aforementioned concept became less popular, with the center of attention on the major risk factor related to GERD shifting from $\mathrm{HH}$ to LES in the early 1970s. ${ }^{19-21}$ Recently, $\mathrm{HH}$ has been reevaluated and studies clarify that $\mathrm{HH}$ is indeed a risk factor for GERD,,$^{4,7,8,11-13}$ and that it may lead to many morbidities such as erosive esophagitis, Barrett's esophagus, adenocarcinoma, etc. ${ }^{4,9-11}$ Nevertheless, in most of the studies, only the HHs measuring over $2.0 \mathrm{~cm}$ in length were considered pathological ${ }^{1,10,11,16,22,23}$ and HHs measuring less than 2.0 $\mathrm{cm}$ have been underestimated, almost neglected, and it was simply considered as a minor alteration in the GEJ anatomy which was not pathologic. ${ }^{4,14}$ To find out the clinical significance of $\mathrm{SSHH}$, we defined it as $\mathrm{HH}$ measuring 0.5 to $2.0 \mathrm{~cm}$ and carried out the study. HHs measuring less than $0.5 \mathrm{~cm}$, which is an arbitrary standard, were excluded from this study since this level of variations seems to occur relatively often during endoscopy.

There has been much debate as to which marker of GEJ 
should be used as the reference point for the presence of $\mathrm{HH}$. Generally, the upper margin of the gastric fold is accepted as GEJ. ${ }^{16,23}$ However, sometimes, endoscopists have difficulty identifying this marker clearly. Endoscopists usually get to observe on the most distal 2-3 cm of the esophagus, identifying longitudinally parallel capillaries running underneath the epithelium. ${ }^{15}$ DeCarvalho took a particular interest in this anatomy and in 1966 he schematically illustrated the angioarchitecture of the lower esophagus, dividing it into four distinct zones. ${ }^{24}$ Later on, these four zones were named as truncal zone, perforating zone, palisade zone (PZ), and gastric zone. ${ }^{25,26}$ In our study, the distal margin of the $\mathrm{PZ}$ was employed as the marker for $\mathrm{GEJ}^{15}$ which has been known to correspond to the GEJ. ${ }^{16,25,26}$

In addition to identifying the distal margin of the $\mathrm{PZ}, \mathrm{SCJ}$ and the site of diaphragmatic pinchcock action were carefully observed to determine the presence of $\mathrm{HH}$ and CLE. ${ }^{15}$ Hoshihara classified the patterns of GEJ into four types according to the relationship of the distal margin of $\mathrm{PZ}$ to SCJ and the site of pinchcock action. ${ }^{27}$ In type A, the distal margin of PZ, SCJ, and the site of pinchcock action all fall at the same level. In type $\mathrm{B}$, the distal margin of $\mathrm{PZ}$ and the site of pinchcock action lie at the same level but SCJ is proximally located. In type $\mathrm{C}$, the distal margin of $\mathrm{PZ}$ and $\mathrm{SCJ}$ concurs but the site of pinchcock action is found distal in relation to them. In type $\mathrm{D}, \mathrm{SCJ}$ is situated proximal to both the distal margin of $\mathrm{PZ}$ and the site of pinchcock action. In our study, CLE was considered to be present in type B and $\mathrm{D}$. And type $\mathrm{C}$ and $\mathrm{D}$ were thought to meet the definition of $\mathrm{HH}$.

We found out that SSHH was similar to LSHH in many aspects. $\mathrm{HH}$ showed male predominance in our study. However, there has been differing reports showing male predominance, ${ }^{28}$ female predominance, ${ }^{29}$ or no difference ${ }^{30-32}$ according to the study populations. As the length of $\mathrm{HH}$ got longer, the diagnosis of erosive esophagitis was made more frequently and the CLE was more frequently found in both $\mathrm{SSHH}$ and $\mathrm{LSHH}$ groups than the group without $\mathrm{HH}$. However, CLE was more frequently found in $\mathrm{SSHH}$ group than in LSHH group. This finding needs further studies for accurate explanation.

There are some limitations to this study. First, measuring the distance of a location using the incisor as the reference point might lack in precision. Even so, considering the degree of flexion of the endoscope and the fact that esophagus exhibits much less elasticity compared to the stomach or duodenum, the length of $\mathrm{HH}$ measured endoscopically using the scope as a ruler could be an reasonable diagnostic method. Second, since biopsy was not performed, we could only apply the term "columnar-lined esophagus" instead of "Barrett's esophagus." According to the latest guidelines related to Barrett's esophagus, its diagnosis requires both the endoscopic identification of CLE and the histologic confirmation of intestinal metaplasia. ${ }^{33-35}$ It would have been more competent if the biopsy had been done in all patients with CLE. Further study is warranted to clarify the significance SSHH on Barrett's esophagus. Third, this analysis was done only with the endoscopic data, and we did not consider the symptoms of the subjects, hence the association between the length of hiatal hernia and non-erosive reflux disease was not assessed. However, the relationship between the length of hiatal hernia and the other two aspects of GERD (i.e., erosive esophagitis and CLE) could be inferred from our study.

The significance of this study is that this is the first report that looked into the clinical significance of $\mathrm{SSHH}$, which has been undervalued and almost neglected. We could observe from our study that $\mathrm{SSHH}$ was comparable to $\mathrm{LSHH}$ in many aspects. Despite the limitations mentioned above, we conclude that $\mathrm{SSHH}$ is not a clinically silent and "innocent entity," but rather a condition with a clinically significant "pathologic entity" quite similar to LSHH as far as GERD is concerned.

\section{References}

1. Mittal RK. Hiatal hernia: myth or reality? Am J Med 1997;103: 33S-39S

2. Mittal RK, Lange RC, McCallum RW. Identification and mechanism of delayed esophageal acid clearance in subjects with hiatus hernia. Gastroenterology 1987;92:130-135.

3. Kahrilas PJ, Lin S, Chen J, Manka M. The effect of hiatus hernia on gastro-oesophageal junction pressure. Gut 1999;44:476-482.

4. Patti MG, Goldberg HI, Arcerito M, Bortolasi L, Tong J, Way LW. Hiatal hernia size affects lower esophageal sphincter function, esophageal acid exposure, and the degree of mucosal injury. Am J Surg 1996;171:182-186.

5. Sloan S, Rademaker AW, Kahrilas PJ. Determinants of gastroesophageal junction incompetence: hiatal hernia, lower esophageal sphincter, or both? Ann Intern Med 1992;117:977-982.

6. Sloan S, Kahrilas PJ. Impairment of esophageal emptying with hiatal hernia. Gastroenterology 1991;100:596-605.

7. Mattioli S, D'Ovidio F, Pilotti V, et al. Hiatus hernia and intrathoracic migration of esophagogastric junction in gastroesophageal reflux disease. Dig Dis Sci 2003;48:1823-1831.

8. Sontag SJ, Schnell TG, Miller TQ, et al. The importance of hiatal hernia in reflux esophagitis compared with lower esophageal sphincter pressure or smoking. J Clin Gastroenterol 1991;13:628-643.

9. Wienbeck M, Barnert J. Epidemiology of reflux disease and reflux esophagitis. Scand J Gastroenterol 1989;156(suppl):7-13.

10. Avidan B, Sonnenberg A, Schnell TG, Chejfec G, Metz A, Sontag 
SJ. Hiatal hernia size, Barrett's length, and severity of acid reflux are all risk factors for esophageal adenocarcinoma. Am J Gastroenterol 2002;97:1930-1936.

11. Cameron AJ. Barrett's esophagus: prevalence and size of hiatal hernia. Am J Gastroenterol 1999;94:2054-2059.

12. Kaul B, Petersen H, Myrvold HE, Grette K, Roysland P, Halvorsen T. Hiatus hernia in gastroesophageal reflux disease. Scand J Gastroenterol 1986;21:31-34.

13. Berstad A, Weberg R, Froyshov Larsen I, Hoel B, Hauer-Jensen M. Relationship of hiatus hernia to reflux oesophagitis. A prospective study of coincidence, using endoscopy. Scand J Gastroenterol 1986;21:55-58.

14. Jeyarajah R, Harford W. Abdominal hernias and gastric volvulus. In: Feldman M, Friedman LS, Brandt LJ, eds. Sleisenger and Fordtran's gastrointestinal and liver disease: pathophysiology, diagnosis, management. 8th ed. Philadelphia: Elsevier, 2006:477-498.

15. Choi DW, Oh SN, Baek SJ, et al. Endoscopically observed lower esophageal capillary patterns. Korean J Intern Med 2002;17:245248.

16. Boyce HW. Endoscopic definitions of esophagogastric junction regional anatomy. Gastrointest Endosc 2000;51:586-592.

17. Armstrong D, Bennett JR, Blum AL, et al. The endoscopic assessment of esophagitis: a progress report on observer agreement. Gastroenterology 1996;111:85-92.

18. Allison PR. Reflux esophagitis, sliding hiatal hernia, and the anatomy of repair. Surg Gynecol Obstet 1951;92:419-431.

19. Cohen S, Harris LD. Does hiatus hernia affect competence of the gastroesophageal sphincter? N Engl J Med 1971;284:1053-1056.

20. Dodds WJ, Dent J, Hogan WJ, et al. Mechanisms of gastroesophageal reflux in patients with reflux esophagitis. $\mathrm{N}$ Engl $\mathrm{J}$ Med 1982;307:1547-1552.

21. Zaninotto G, DeMeester TR, Schwizer W, Johansson KE, Cheng SC. The lower esophageal sphincter in health and disease. Am J Surg 1988;155:104-111.

22. Fein M, Ritter MP, DeMeester TR, et al. Role of the lower esophageal sphincter and hiatal hernia in the pathogenesis of gastroesophageal reflux disease. J Gastrointest Surg 1999;3:405-410.

23. McClave SA, Boyce HW Jr, Gottfried MR. Early diagnosis of columnar-lined esophagus: a new endoscopic diagnostic criterion.
Gastrointest Endosc 1987;33:413-416.

24. De Carvalho CA. Sur l'angioarchitecture veineuse de la zone de transition oesophagogastrique et son interpretation functionnelle. Acta Anat 1966;64:125-162.

25. Spence RA. The venous anatomy of the lower oesophagus in normal subjects and in patients with varices: an image analysis study. $\mathrm{Br} \mathrm{J}$ Surg 1984;71:739-744.

26. Vianna A, Hayes PC, Moscoso G, et al. Normal venous circulation of the gastroesophageal junction. A route to understanding varices. Gastroenterology 1987;93:876-889.

27. Hoshihara Y. Complications of gastroesophageal reflux disease. 2. Endoscopic diagnosis of Barrett esophagus - can Barrett esophagus be diagnosed by endoscopic observation alone? Nippon Naika Gakkai Zasshi 2000;89:85-90.

28. Yeom JS, Park HJ, Cho JS, Lee SI, Park IS. Reflux esophagitis and its relationship to hiatal hernia. J Korean Med Sci 1999;14:253-256.

29. Loffeld RJ, van der Putten AB. Hiatal hernia, reflux oesophagitis, and Barrett's oesophagus. Hiatal hernia, refluxoesophagitis, and Barrett's oesophagus. A retrospective endoscopic and clinical study. Dis Esophagus 1993;6:57-61.

30. Furukawa N, Iwakiri R, Koyama T, et al. Proportion of reflux esophagitis in 6010 Japanese adults: prospective evaluation by endoscopy. J Gastroenterol 1999;34:441-444.

31. Kang JY, Ho KY. Different prevalences of reflux oesophagitis and hiatus hernia among dyspeptic patients in England and Singapore. Eur J Gastroenterol Hepatol 1999;11:845-850.

32. Loffeld RJ, van der Putten AB. Newly developing hiatus hernia: a survey in patients undergoing upper gastrointestinal endoscopy. J Gastroenterol Hepatol 2002;17:542-544.

33. Sharma P, McQuaid K, Dent J, et al. A critical review of the diagnosis and management of Barrett's esophagus: the AGA Chicago Workshop. Gastroenterology 2004;127:310-330.

34. Wang KK, Sampliner RE. Updated guidelines 2008 for the diagnosis, surveillance and therapy of Barrett's esophagus. Am J Gastroenterol 2008;103:788-797.

35. Hirota WK, Zuckerman MJ, Adler DG, et al. ASGE guideline: the role of endoscopy in the surveillance of premalignant conditions of the upper GI tract. Gastrointest Endosc 2006;63:570-580. 